Article

\title{
Fragility Curves of the Urban Road Network Based on the Debris Distributions of Interfering Buildings
}

\author{
Angelo Anelli ${ }^{1}\left[\right.$, Federico Mori ${ }^{1}$ and Marco Vona ${ }^{2, *}$ (I) \\ 1 Italian National Research Council-IGAG, Montelibretti, 00010 Rome, Italy; angelo.anelli@igag.cnr.it (A.A.); \\ federico.mori@igag.cnr.it (F.M.) \\ 2 Department of Civil Engineering, University of Basilicata, 85100 Potenza, Italy \\ * Correspondence: marco.vona@unibas.it
}

Received: 14 January 2020; Accepted: 13 February 2020; Published: 14 February 2020

\begin{abstract}
Fragility curves are essential tools to quantitatively assess the physical vulnerability of structures and infrastructures at risk for a given seismic hazard. They describe the probability of exceeding a given performance level under earthquake excitation, and are usually defined by a lognormal probability distribution function. Although debris from damaged buildings adjacent to road edges is the main cause of urban mobility disruption, studies on the fragility curves development for infrastructures subject to seismic actions focus on geotechnical effects, and do not analyze this type of road blockage. The article proposes an analytical procedure to construct fragility curves for urban road networks. It is based on the construction of debris graphs and the use of an appropriate fitting technique. For a given seismic intensity measure level, the developed fragility curves express the probability that the road is open or closed to the transit of emergency vehicles after debris fall. Therefore, the performance level is defined in terms of the width of the road pavement that remains free after the debris fall, or the width of the debris heap on the road pavement. Finally, the proposed framework is tested with real data of the main street in Amatrice, and the results are presented and discussed.
\end{abstract}

Keywords: fragility curves; urban road network; road closure probability; damages buildings; debris distribution; seismic risk analysis; emergency management

\section{Introduction}

Earthquakes often trigger the closure of the road network, causing obstacles in rescue and evacuation procedures. Efficient mitigation strategies and appropriate emergency plans should consider the probability of road closures in order to ensure rapid emergency management, and to minimize the impact of disasters in terms of casualties, the disruption of activities, and economic losses. Although there are growing studies on the accessibility modeling of road networks for the essential elements of emergency management in earthquake cases, such as operational centers, hospitals, fire stations and emergency areas, the literature that incorporates road closure probabilities into the accessibility analysis is quite limited. An interesting integration can be found in Ertugay et al. [1].

In the aftermath of a disastrous seismic event, road blockages can be direct or indirect (Figure 1). The former directly affects the road pavement due to ground failures from liquefaction, landslides, and fault ruptures, or through the structural damage of its additional components (bridges, tunnels, retaining walls, etc.), while the latter are due to the debris distribution generated by the collapse of the surrounding environment. 


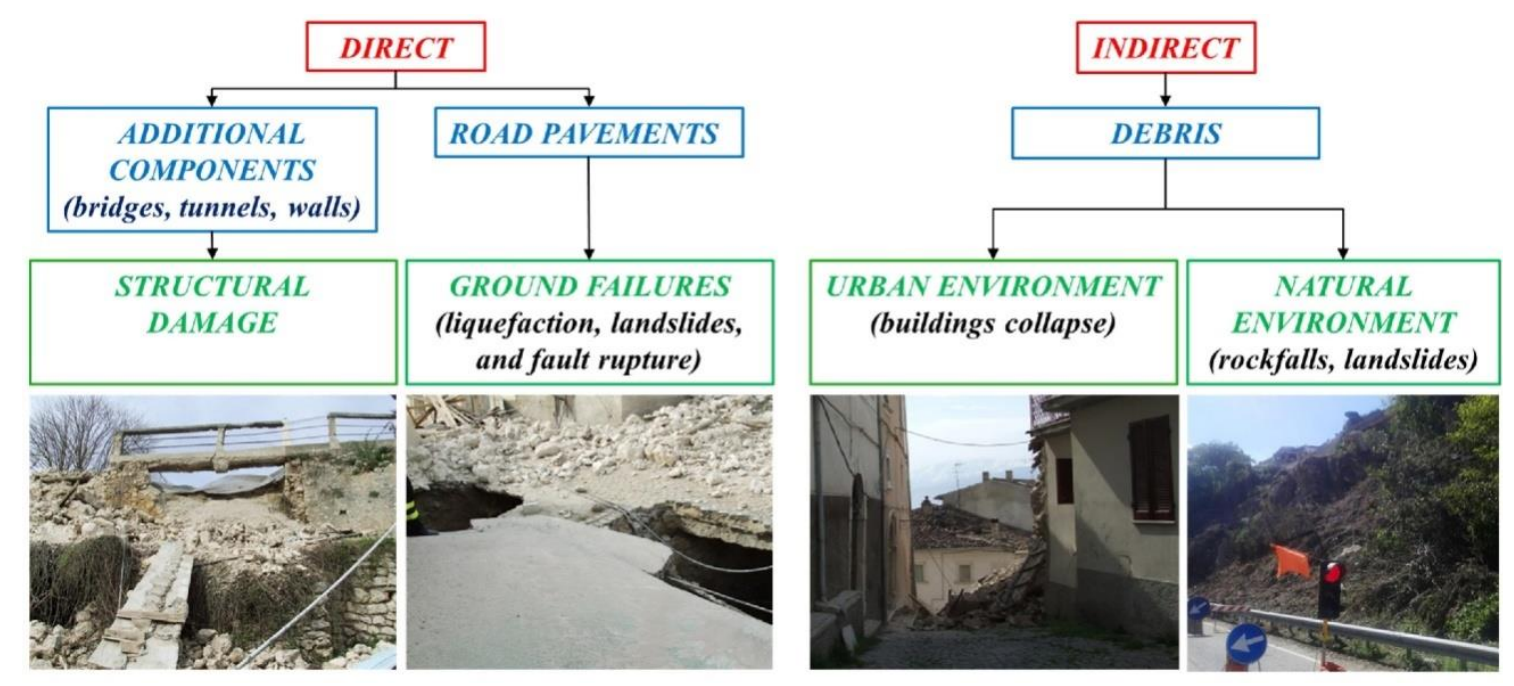

Figure 1. Types of road blockages.

Generally, outside inhabited centers, this distributed debris is due to the collapse of elements in the natural environment (rockfalls and landslides), while inside inhabited centers, it is caused by the collapse of buildings adjacent to road edges (interfering buildings). In urban areas, road blockages due to collapsed buildings are the most important mobility limitation for the road network [2,3]. Therefore, the vulnerability of interfering buildings plays a key role in assessing the seismic risk of an urban road network.

In Argyroud et al. [4], a summary is provided of the different methodologies to develop fragility curves for transportation infrastructures subject to seismic activity; however, the authors focused on the geotechnical effects, and did not consider road blockages from damage to interfering buildings.

Analyzing the collapsed buildings triggered by the earthquakes that occurred between 1988 and 2003 in Algeria, Armenia, India, Japan, Mexico, Romania, Taiwan and Turkey, researchers [5] considered ten different damage types categorized into the following five groups (Figure 2): (i) inclined layers; (ii) pancake collapses; (iii) debris heaps; (iv) overturn collapses; and (v) overhanging elements.

In the group "inclined layers", the structure supporting a floor slab or a flat roof collapses on one side, generating an inclined plane that can affect one floor, several floors, or the whole building. "Pancake collapses" are due to the uniform collapse of the structural elements of a floor or of all or some floors (so-called soft storeys). These collapses are typical of reinforced concrete (RC) buildings. They generate modest debris areas on the road pavement. In the group "debris heaps", all or some of the structural elements are completely destroyed, generating significant debris areas. Commonly, such collapses are typical of masonry buildings. "Overturn collapses" are characterized by two types of damage, namely "overturn collapse-separated" and "overturn collapse". In the first damage type, the building footprint area is still recognizable, but a new structure (the upper part of the building) can be found nearby. In the second damage type, the building maintains a single body, but the inclination of its vertical axis is changed until the building is completely overturned (in urban areas, complete overturning is often prevented by the surrounding buildings or debris). For this damage type, soil conditions play an important role. Finally, in the "overhanging elements" group, the load-bearing external walls are destroyed, but the floor slab or the roof remains in its initial position. Depending upon the building type ( $\mathrm{RC}$, masonry, etc.), the five groups highlight the need to consider certain appropriate predictive models capable of assessing the debris area of the collapsed buildings and their possible distributions around the damaged building. 
i) Inclined layers

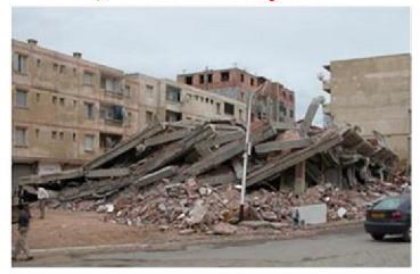

1) inclined Plane

2) multi layer collapses

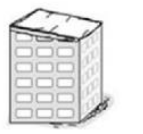

3) outspread multi layer collapse

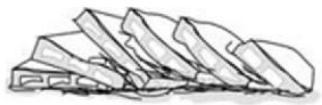

ii) Pancake collapses

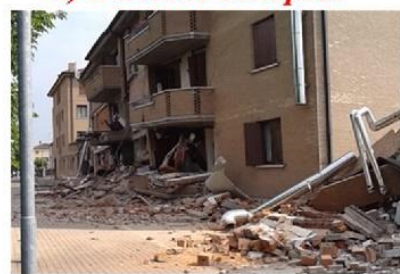

$4 a, b, c)$ one storey

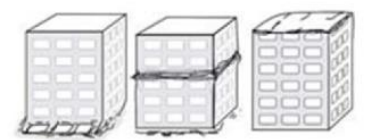

5) and $5 a, b, c)$ all/several storeys

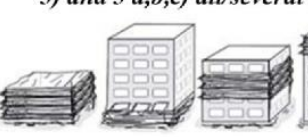

iii) Debris heaps

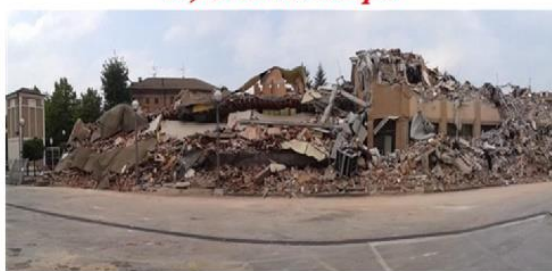

6) on uncollapsed storeys 7a) with small debris
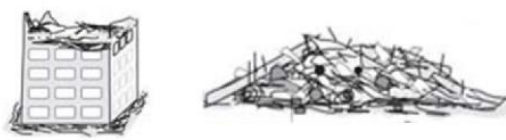

7b) with plates

7c) with vertical elements

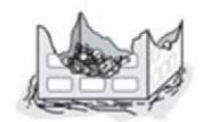

iv) Overturn collapse

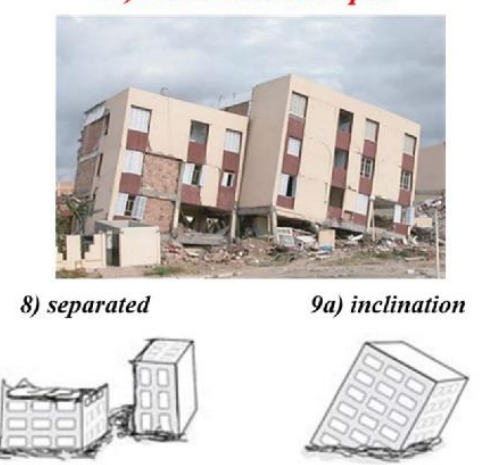

9b) complete overtun

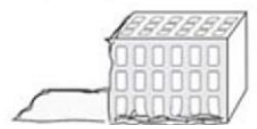

v) Overhanging elements

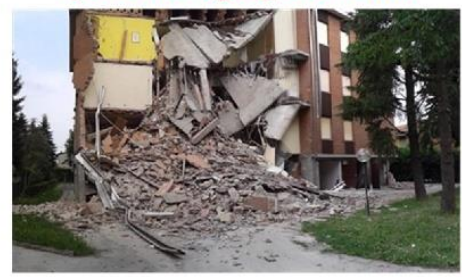

10) destroyed supporting external walls

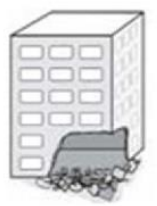

Figure 2. Classification of collapsed buildings as reported in Schweier C. and Markus M. [5].

This work aims to evaluate the probability of the opening or closure of the urban road network in the emergency management phase through a methodology that allows fragility curves to be generated based on the debris distribution of interfering buildings. To the authors' knowledge, there are no fragility curves that interpret this phenomenon. In particular, these curves should express, for a given seismic intensity measure (IM) level, the probability that the width of the road pavement is at least $3.50 \mathrm{~m}$, in order to allow the passage of emergency vehicles after a debris fall.

The proposed methodology is specifically tailored for a minimum amount of information provided by the analysis of the limiting conditions of the emergency (LCE). This analysis was formulated in 2012 by the Italian Civil Protection Department [6,7]. Based on a limited amount of information, the analysis identifies those physical elements (strategic buildings $=$ ESs, emergency areas = AEs, road network segments $=$ RAs, structural units = USs, structural aggregates $=$ ASs) strictly necessary for the emergency management of an urban settlement. Together with LCE, these minimal physical elements are assimilated within a network of arcs and nodes, where arcs are the road network segments.

\section{Methodology}

The proposed methodology is valid for RC and masonry buildings, and has been validated for post-earthquake observations and experimental literature data. It can be developed into four key steps:

Step 1. Definition and characterization of the road type; 
Step 2. Assignment of vulnerability functions;

Step 3. Construction of debris graphs;

Step 4. Construction of a fragility curve for each road segment.

Step 1. Definition and characterization of the road type.

In order to define the type of road related to the road network segments of the urban settlement, it is necessary to identify the following:

(i) The geometric characteristics of the analyzed road segment (the average width of the road pavement $\left(w_{r}\right)$, the average width of the sidewalks $\left(w_{b r}\right)$, and the average distance between the opposite interfering buildings $\left(w_{b b}\right)$ along the road sides);

(ii) the types of interfering buildings constituting the structural aggregates or isolated structural units (structural material, number of floors, age of the building);

(iii) the geometric characteristics of the structural aggregates or of the interfering isolated structural unit (average height of the roof covering $\left(h_{b}\right)$ and the footprint dimensions in transversal $(a)$ and longitudinal ( $b$ ) directions).

This information can be easily found in the LCE analysis of RAs, USs and Ass, as well as through satellite images.

Step 2. Assignment of vulnerability functions.

Once the types of interfering buildings constituting the structural aggregates or the isolated structural units are identified, two or more vulnerability functions should be assigned for each side of the road. In this way, the typological differences of the structural units constituting the aggregates and all those characteristics (structural and architectural systems, building use, and structural regularity/irregularities), not easily identifiable during the field survey necessary for the LCE analysis, can be taken into account.

Vulnerability functions express the relationship between the selected IM (e.g., peak ground acceleration, PGA) and the damage factor (DF), where the letter represents the expected average ratio of the repair cost to the replacement cost of the building. Such vulnerability functions can be defined using the methodologies and results of scientific literature (interesting approaches for structural aggregates and/or structural units can be found in [8-10]), or utilizing datasets and catalogs that are available on web platforms as resources for open risk modeling. Alternatively, they can be generated by sets of fragility curves using, for example, the following expression:

$$
D F=\sum_{i=1}^{n} D F_{d s_{i}} \cdot P\left(d s_{i} \mid I M\right)
$$

where $n$ is the number of damage states considered; $D F_{d s_{i}}$ is the mean damage factor value for a given damage state $d s_{i}$ (using, for example, the collected values from the vulnerability literature [11]); $P\left(d s_{i} \mid I M\right)$ is the probability of a building of sustaining the damage state $d s_{i}$ for a specific level of $I M$. Another interesting approach to define vulnerability functions from fragility curves can be found in Vona et al. [12]. Obviously, the vulnerability functions or the fragility curves used should represent the structural types and the real conditions of the analyzed buildings.

Step 3. Construction of debris graphs.

For each assigned vulnerability function, it is necessary to construct different graphs of debris width $\left(w_{d}\right)$ extending further than the initial width of the structure $(a)$, in order to consider the possible debris distributions around the damaged building. These graphs express the relationship between the selected IM and the debris heap width resulting from building damage.

As shown in Figure 3, using the assigned vulnerability functions, it is possible to define the IM value in which a certain performance level is reached, thanks to the $D F$ values provided by the Italian 
guidelines for the classification of the seismic risk of buildings [13,14], the so-called SISMABONUS. These DF values are shown in Table 1 . They are valid for typical RC and masonry buildings with residential use, and can conventionally be used for buildings with different uses or structural materials.

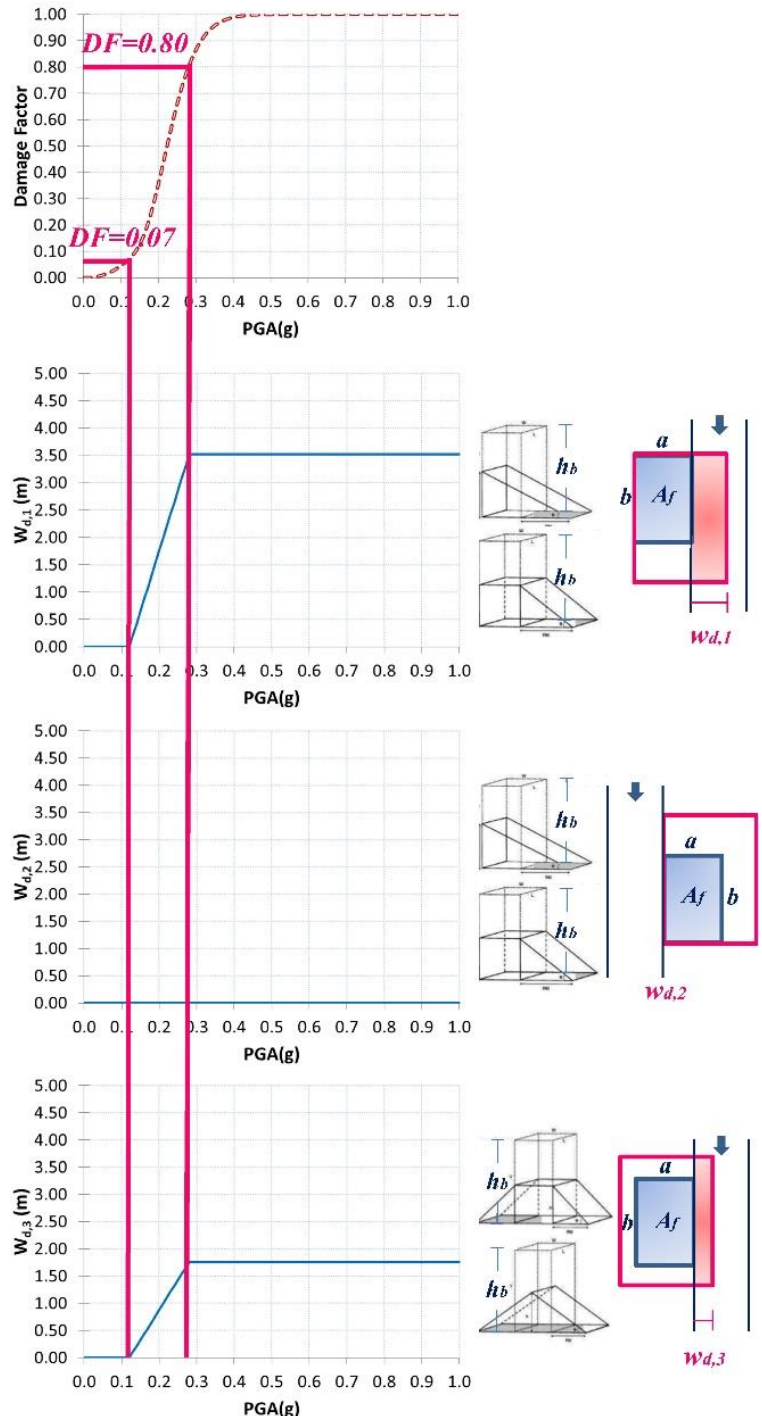

(a)

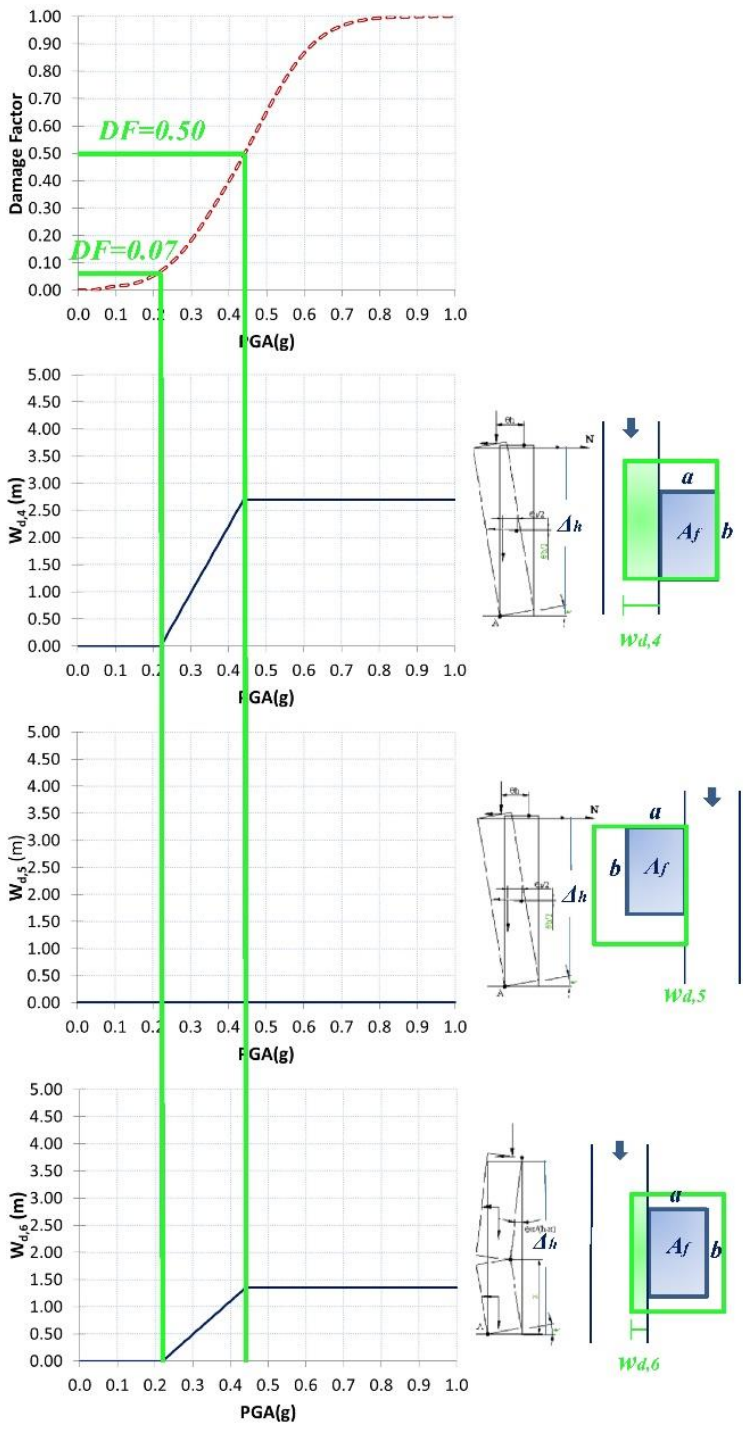

(b)

Figure 3. Construction of debris graphs for (a) masonry buildings and (b) reinforced concrete (RC) buildings. peak ground acceleration (PGA) is peak ground acceleration.

Table 1. Threshold values provided by the Italian guidelines $[9,10]$.

\begin{tabular}{|c|c|c|c|c|c|c|}
\hline Performance Level: & IDLS $^{2}$ & OLS $^{3}$ & DLS $^{4}$ & SLS $^{5}$ & $\mathrm{CLS}^{6}$ & $\mathrm{RLS}^{7}$ \\
\hline Damage Factor (DF) $^{\mathbf{1}}$ : & $0 \%$ & $7 \%$ & $15 \%$ & $50 \%$ & $80 \%$ & $100 \%$ \\
\hline
\end{tabular}

According to the current Italian seismic code [15] (NTC 2018 hereafter), in the event of an earthquake, any building meeting the operative limit state (OLS) is considered to have no damage to its structural elements and only minor damage to its non-structural elements. Therefore, for this damage state, the building should not suffer significant damage, so as to produce appreciable debris on the road. Consequently, consistent with Table 1, for each $I M$ in which $D F \leq 7 \%$, the structure retains 
its footprint area $\left(A_{f}\right)$, and the debris width can be assumed equal to zero $\left(w_{d}=0\right)$. For damage beyond the OLS, the structure instead has a different behavior.

For masonry buildings (Figure 3a), it is assumed that the maximum debris area $\left(A_{d, \max }\right)$ is reached in the collapse limit state (CLS). Such debris area encompasses the building footprint area and the relative debris heap on the road. Meeting this limit state, $A_{d, \max }$ remains constant, while the angle of inclination of the debris heap (therefore the debris volume $V_{b}$ ) increases up to the maximum $D F$ value $(100 \%)$. In the transition from OLS to CLS, it is assumed that the $A_{d}$ grows linearly with the increasing $I M$. In order to evaluate the maximum debris area in the SLC, it is possible to use the methodology developed by Domaneschi et al. [16]. Based on the geometric and typological characteristics of the masonry buildings of central Italy (building size, wall thickness, arrangement of openings, indoor spaces distribution, etc.), in [16], the debris area of collapsed buildings was determined by using an amplification factor $(\varepsilon)$ of the building footprint area, which depended on the geometric characteristics of the structure. In particular, $A_{d, \max }$ and $\varepsilon$ can be calculated as follows:

$$
\begin{gathered}
A_{d, \max }=A_{f} \cdot \varepsilon^{2} \\
\varepsilon=1.228+0.07869 \cdot\left(\frac{a}{b}\right)+0.05626 \cdot\left(\frac{A_{f}}{V_{b}} \cdot \frac{h_{b}^{2}}{a}\right)
\end{gathered}
$$

where $a, b, h_{b}, A_{f}=a \cdot b$, and $V_{b}=a \cdot b \cdot h_{b}$ can be assumed to be the geometric characteristics of the structural aggregates or of the interfering isolated structural unit (see step 1). The debris area can have different distributions around the damaged building. To take into account the uncertainty of the possible distributions, it is possible to use the simplified collapse models proposed by some authors $[17,18]$. These models correspond to a collapsed building in one or two directions. Consequently, an equation that estimates the debris width $\left(w_{d}\right)$ can be defined for each debris distribution. For the models corresponding to a collapsed building in one direction, the corresponding $w_{d}$ can be evaluated as follows:

$$
\begin{gathered}
w_{d, 1}=w_{d, \max }=a \cdot(\varepsilon-1) \\
w_{d, 2}=0
\end{gathered}
$$

where $w_{d, 2}$ describes the case in which the debris distribution, which does not affect the analyzed road network segment. For the collapsed building in two directions, the relevant $w_{d}$ can be calculated as follows:

$$
w_{d, 3}=\frac{w_{d, \max }}{2}=\frac{a \cdot(\varepsilon-1)}{2}
$$

Based on observations from past earthquakes, the main debris distribution of RC buildings is due to the collapse of nonstructural elements. For these buildings (Figure 3b), it is therefore assumed that the maximum debris area is reached in the life safety limit state (SLS), beyond which the debris area remains constant, while debris volume increases up to the maximum $D F$ value. This assumption is justified by the fact that, according to NTC 2018, in meeting the SLS, the failure of nonstructural components is expected. In the transition from OLS to SLS, it is assumed that the debris area grows linearly with increasing IM. The infill panels may not collapse on the analyzed road network segment, or they may collapse with complete or partial overturning. To take into consideration the randomness of these collapse mechanisms, in this case it is also possible to assign different graphs of the debris widths. In order to calculate the debris widths expected in SLS, the following expressions are suggested:

$$
\begin{gathered}
w_{d, 4}=\Delta h \\
w_{d, 5}=0 \\
w_{d, 6}=\frac{\Delta h}{2}
\end{gathered}
$$


where $\Delta h$ is the average height of the infill panels or approximately the average floor height of the structure. Equations (7) and (9) correspond to collapse mechanisms with complete or partial overturning, respectively, while Equation (8) considers the case in which the overturning of the infill panels does not affect the analyzed road network segment. For example, this case can also be found in pancake collapses in which there is a minimal debris area.

For each assigned vulnerability function, three graphs of debris width should be constructed in order to take into account the possible debris distributions around the damaged building. For each debris distribution, the graph is built based on the debris widths and $I M$ values in which the considered building performance levels are reached. These performance levels can be identified with the $D F$ threshold values shown in Table 1 on the DF values axis of the vulnerability function. According to the assumptions of the proposed methodology, for each $I M$ in which $D F \leq 7 \%$, the debris width can be assumed equal to zero $\left(w_{d}=0\right.$ ), while for each $I M$ in which $D F \geq 80 \%$ (for a masonry building) or $D F \geq$ $50 \%$ (for an RC building), the debris width can be defined using Equations (4)-(6) for the masonry building, or Equations (7)-(9) for the RC building. Based on these boundary conditions, a reasonable assumption can be made that for the other $I M$ values, the debris width varies with a linear law, and the generic graph of debris width can be defined.

Step 4. Construction of the fragility curve for each road segment.

Considering the geometric characteristics of the analyzed road network segment, and comparing the debris graphs related to the interfering buildings constituting the considered structural aggregate along the road edges, for each $I M$ it is possible to determine different width values of the road pavement that remains free after the debris fall $\left(w_{f r}\right)$, using the following expression (Figure 4$)$ :

$$
w_{f r}=w_{b b}-\max \left(w_{b r 1} ;\left|w_{b r 1}-w_{d 1, i}\right|\right)-\max \left(w_{b r 2} ;\left|w_{b r 2}-w_{d 2, j}\right|\right)
$$

where $w_{b b}$ is the average distance between the opposite interfering buildings along the road sides, $w_{b r} 1$ and $w_{b r 2}$ are the average widths of the sidewalk on side 1 and 2 of the road, respectively, $w_{d 1, i}$ is the debris width of the $i$-th debris graph related to the structural aggregates on side 1 , and $w_{d 2, j}$ is the debris width of the $j$-th debris graph pertaining to the structural aggregates on side 2 .

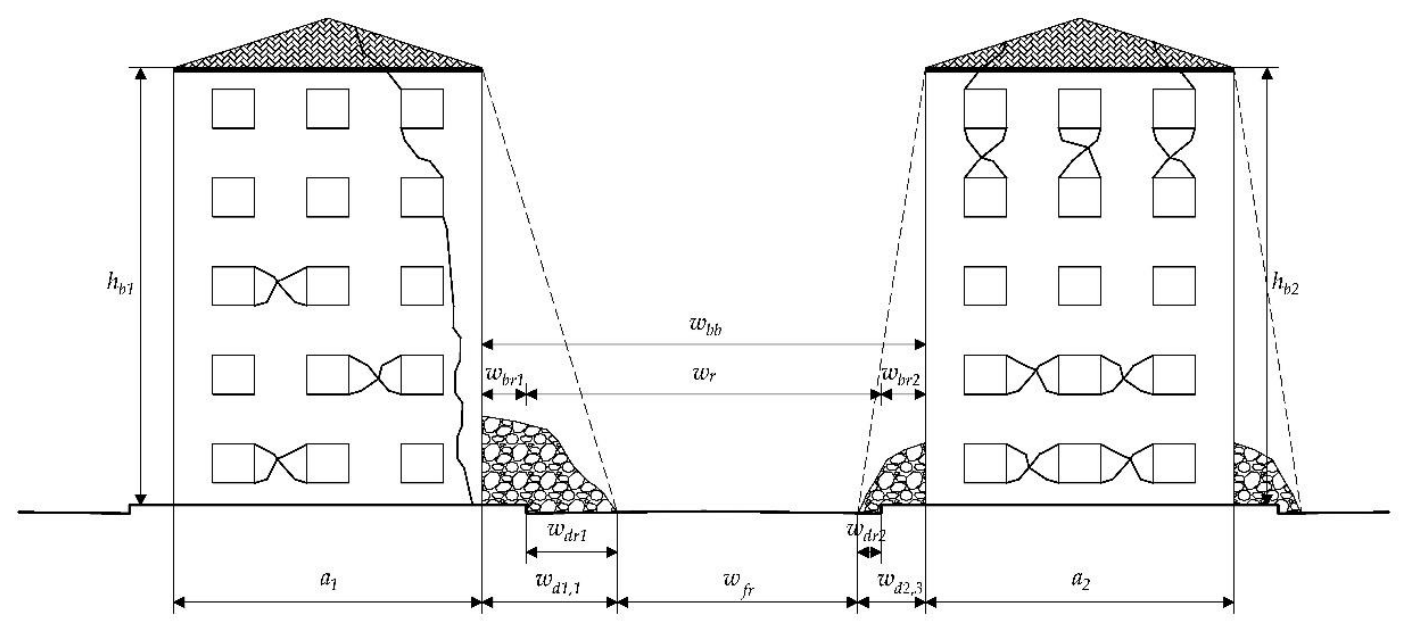

Figure 4. Geometric characteristics.

As shown in Figure 5, by applying Equation (10) for each IM considered, it is possible to identify the total number of analysis points and the number of points where the width of the road pavement is reduced beyond the $3.50 \mathrm{~m}\left(w_{f r} \leq 3.50 \mathrm{~m}\right)$, required for the passage of emergency vehicles (number of closures or collapses). In particular, for these closures or collapse points, the required performance 
level can be defined through the width of the debris heap on the road pavement $\left(w_{d r}\right)$, which can assume the following values:

$$
w_{d r} \geq w_{r}-3.50
$$

where $w_{r}$ is the average width of the road pavement expressed in meters. The proposed methodology, therefore, concludes by applying a statistically appropriate method for fitting the fragility curve to all these points.

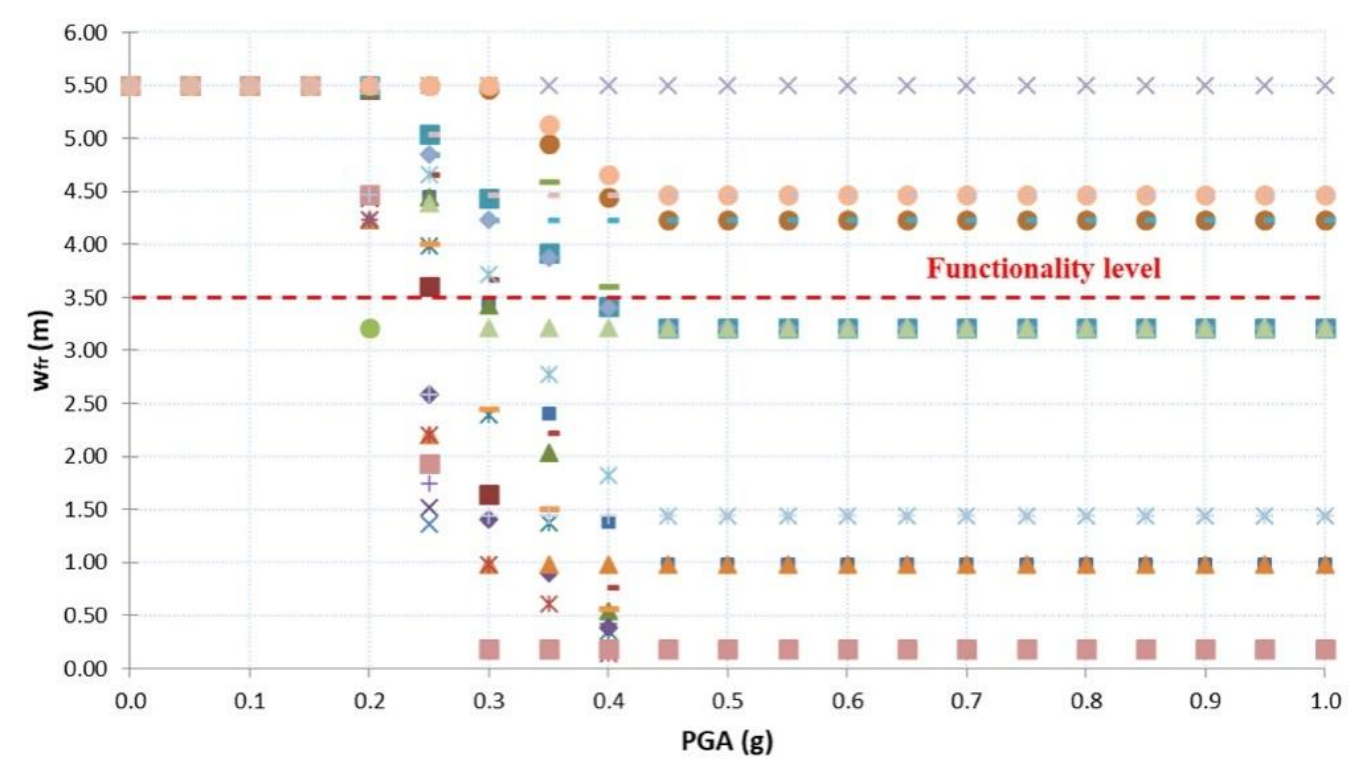

Figure 5. Example of width values of the road pavement that remains free after the debris fall $\left(w_{f r}\right)$ for a given set of intensity measure (IM) levels.

Fragility curves are usually described by a lognormal probability distribution function according to the following equation:

$$
P\left(P L \geq P L_{i} \mid I M\right)=\Phi\left[\frac{1}{\beta} \cdot \ln \left(\frac{I M}{\theta}\right)\right]
$$

where $P\left(P L \geq P L_{i} \mid I M\right)$ is the probability of exceeding a particular performance level, $P L$, for a given $I M, \Phi$ is the standard cumulative probability function, $\beta$ is the standard deviation of the natural logarithm of $I M$ for the performance level, and $\theta$ is the median threshold value of $I M$ required to cause the performance level. According to Equation (12), the development of fragility curves requires the estimation of two parameters, namely $\theta$ and $\beta$.

At each intensity level $I M=x_{j}$, the proposed procedure provides a certain number of closures or collapses out of a total number of analyses. In order to estimate the fragility curve parameters, the appropriate fitting technique for this type of data is to use the method of maximum likelihood estimation [19]. More specifically, the estimate of the fragility function parameters is obtained by maximizing the logarithm of the likelihood function as follows:

$$
\{\theta, \beta\}=\underset{\theta, \beta}{\operatorname{argmax}} \sum_{j=1}^{m}\left\{\ln \left(\begin{array}{c}
n_{j} \\
z_{j}
\end{array}\right)+z_{j} \ln \Phi\left(\frac{\ln \left(x_{j} / \theta\right)}{\beta}\right)+\left(n_{j}-z_{j}\right) \ln \left(1-\Phi\left(\frac{\ln \left(x_{j} / \theta\right)}{\beta}\right)\right)\right\}
$$

where $m$ is the number of $I M$ levels and $z_{j}$ is the number of collapses out of $n_{j}$ ground motions with $I M=$ $x_{j}$. To solve Equation (13), Baker [19] implemented simple software tools for the calculations. The user only needs to provide observed data on the $I M$ levels considered, and the relevant numbers of analyses and collapses, and the software tools estimate the fragility curve parameters. An application example of this analysis is provided by the same author in order to obtain the fragility curves of structures with 
a minimal number of structural analyses. Obviously, IM levels should focus the fitting on the region of the fragility curve most important for risk assessments, rather than considering analysis at high or low $I M$ levels. They can be defined according to the seismic hazard of the study area. Figure 6a shows the fragility curve construction for a generic road network segment using the aforementioned software tools and the plotted data in Figure 5.

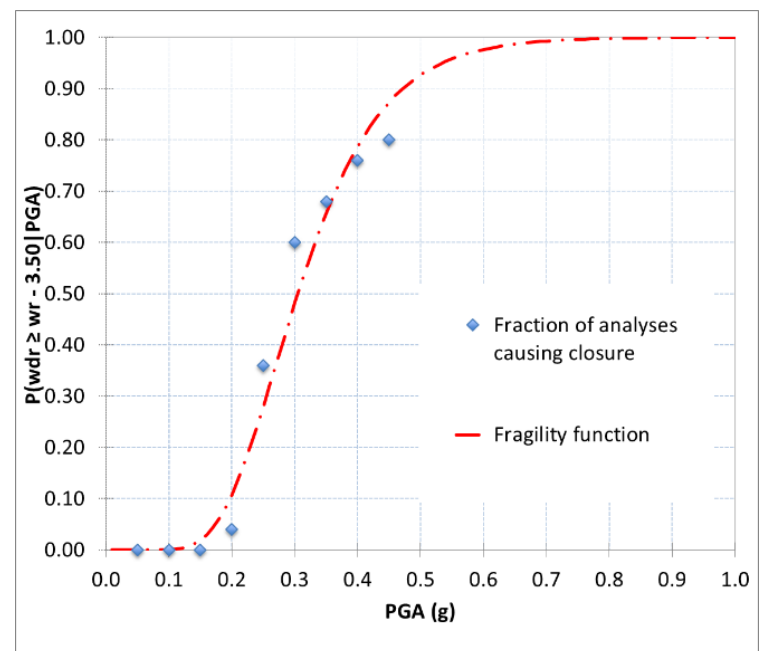

(a)

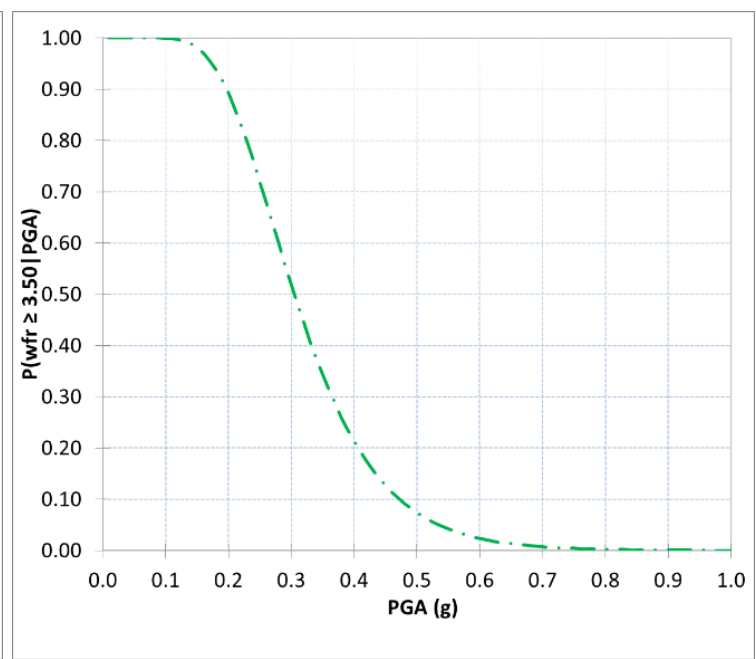

(b)

Figure 6. Fragility curve of a generic urban road segment in terms of (a) probability of closure and (b) probability of opening.

Based on the fragility curve in terms of the probability of closure $P\left(w_{d r} \geq w_{r}-3.50 \mid I M\right)$, for each $I M$, the probability that the width of the road pavement is at least $3.50 \mathrm{~m}$ to allow the passage of emergency vehicles after debris fall $P\left(w_{f r} \geq 3.50 \mid I M\right)$, can be evaluated as follows:

$$
P\left(w_{f r} \geq 3.50 \mid I M\right)=1-P\left(w_{d r} \geq w_{r}-3.50 \mid I M\right)
$$

Figure $6 \mathrm{~b}$ shows the relevant fragility curve. Consistent with LCE analysis, this type of fragility curve can be used directly to assess the operational efficiency of the road network segments (RAs), providing a quantitative measure of the probability to preserve their efficiency after a seismic event with a given IM level.

\section{Case Study}

The proposed methodology was applied to a case study of the "Corso Umberto I" in Amatrice, Italy. Amatrice extends along the East-West direction with parallel roads and is crossed by Corso Umberto I, the main street of the city. Corso Umberto I is located in the historic center of the city. Although it plays a key role in the LCE analysis of the municipality of Amatrice, the earthquakes that hit Central Italy on 24 August, 26 October, and 30 October 2016 triggered major damage, mostly to buildings and architectural heritage structures along the road, causing closure of the road already with the seismic events of 24 August. More specifically, two shocks were felt on 24 August: the main shock at 3:36 a.m. (local time) with magnitude $\mathrm{Mw}=6.2$ and epicenter close to Accumoli (Rieti province), and the aftershock at 4.33 a.m. with a magnitude $\mathrm{Mw}=5.5$ and epicenter close to Norcia (Perugia province) [20]. According to the Italian Civil Protection Department [21], these seismic events caused a total of 299 fatalities, and 386 people were injured and about 4800 rendered homeless.

Based on LCE analysis, Corso Umberto I consisted of two road network segments (AC1 and AC2). In addition, there were eight interfering structural aggregates and one isolated structural unit along the road. Using the LCE information available on the web-GIS platform [22], all data were found for each road segment and structural aggregate in order to identify their geometric and typological 
characteristics. More specifically, AC1 and AC2 had an average width of road pavement of $5.50 \mathrm{~m}$ $\left(w_{r}=5.50 \mathrm{~m}\right)$, an average width of sidewalks of $1.00 \mathrm{~m}$ on each side $\left(w_{b r 1}=w_{b r 2}=1.00 \mathrm{~m}\right)$, and an average distance between the opposite interfering buildings along the road sides of $7.50 \mathrm{~m}\left(w_{b b}\right.$ $=7.50 \mathrm{~m}$ ). In terms of structural aggregates, there were 100 masonry buildings and only three RC buildings (the debris of masonry buildings was clearly prevalent). The buildings had a covered area of approximately 15,600 square meters. They varied from one to four storeys. Depending on the geometric and typological characteristics of the aggregates, the critical areas of AC1 and AC2 are circled in red in Figure 7 (road segment between aggregate 1 and 2 for $\mathrm{AC} 1$ and road segment between aggregate 4 and 6 for AC2). According to Equations (2)-(4), in these areas the structural aggregates reached their maximum debris widths along the infrastructures considered. These critical areas were the road portions with higher risk of loss of connectivity. The maximum area and width of the debris $\left(w_{d, \max }\right)$ for each structural aggregate in the critical areas are shown in Table 2.

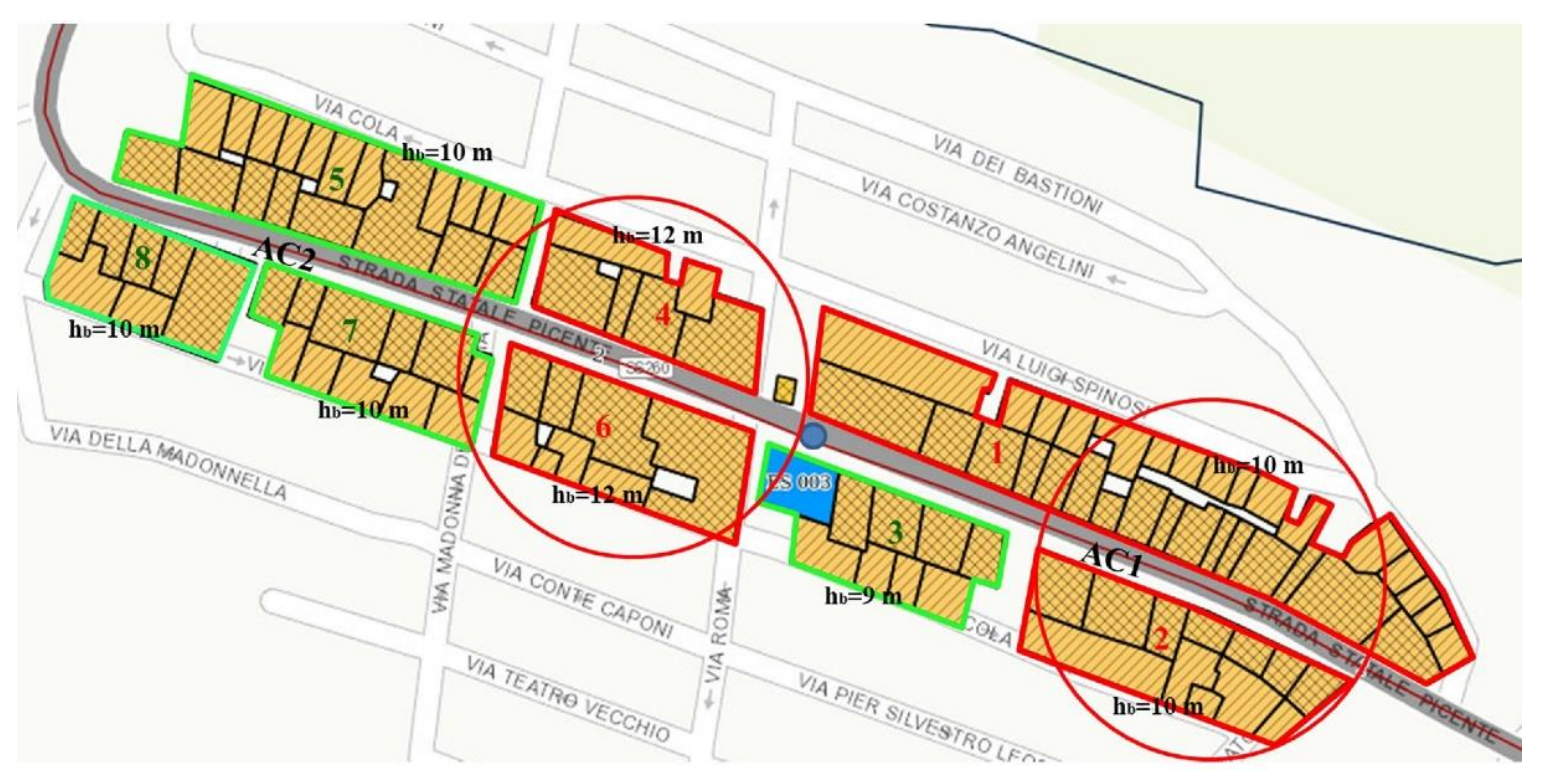

Figure 7. Road segments and structural aggregates in "Corso Umberto I" according to the limiting conditions of the emergency (LCE) analysis of the municipality of Amatrice [22].

Table 2. The areas and widths of the debris for the considered structural aggregates.

\begin{tabular}{ccccccc}
\hline Aggregate & $\boldsymbol{a}(\mathbf{m})$ & $\boldsymbol{b}(\mathbf{m})$ & $\boldsymbol{h}_{\boldsymbol{b}}(\mathrm{m})$ & $\varepsilon$ & $A_{\boldsymbol{d}, \text { max }}\left(\mathrm{m}^{\mathbf{2}}\right)$ & $\boldsymbol{w}_{\boldsymbol{d}, \text { max }}(\mathrm{m})$ \\
\hline 1 & 24.89 & 170.00 & 10.00 & 1.26 & 6739.82 & 6.52 \\
2 & 22.08 & 84.00 & 10.00 & 1.27 & 3011.58 & 6.05 \\
4 & 21.66 & 59.50 & 12.00 & 1.29 & 2137.76 & 6.24 \\
6 & 26.68 & 63.00 & 12.00 & 1.29 & 2782.75 & 7.65 \\
\hline
\end{tabular}

In order to describe the different seismic behaviors of the buildings constituting the structural aggregates present in the critical area of $\mathrm{AC} 1$ and $\mathrm{AC} 2$, six types of fragility curves were selected, and consequently, using Equation (1), six vulnerability functions were generated and assigned for both sides of the two road segments (Figure 8). In particular, using the OpenQuake platform [23], the fragility curves developed by Ahmad et al. [24] were selected, which were analytical fragility functions for masonry buildings and building aggregates expressed in terms of PGA. According to these authors, the prototypical buildings represent Euro-Mediterranean buildings in general, and Italian and Slovenian buildings in particular. The fragility curves used were valid for unreinforced masonry buildings with low and high void percentages and for stone buildings of two and four storeys, respectively. 
Fired clay hollow bricks - High Percentage Voids - 2 storeys
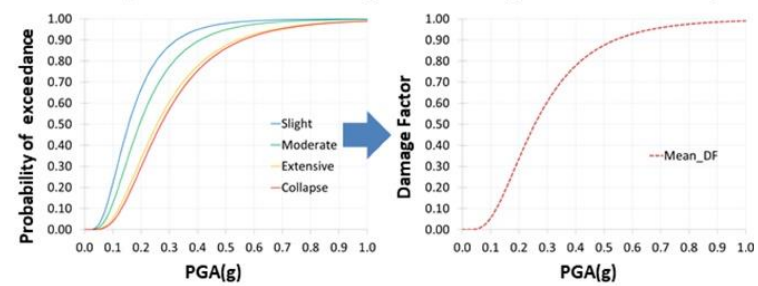

Fired clay hollow bricks - Low Percentage Voids - 2 storeys

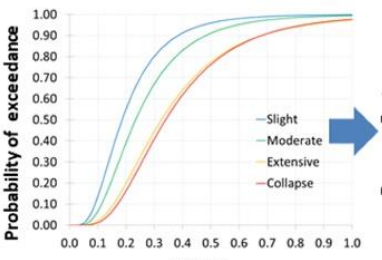

PGA(g)

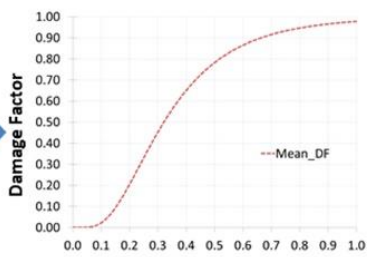

PGA(g)

Stone -2 storeys
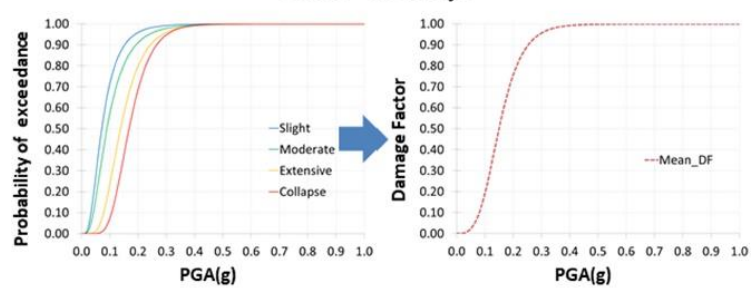

(a)
Fired clay hollow bricks - High Percentage Voids - 4 storeys

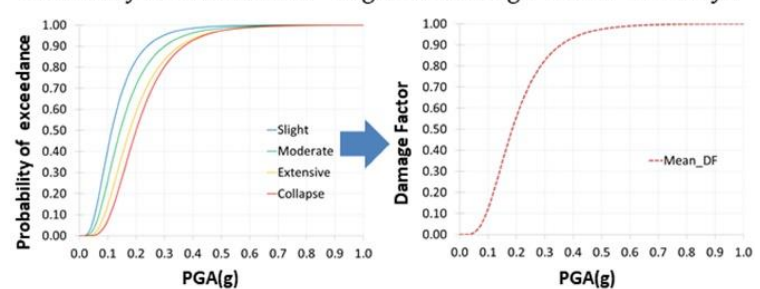

Fired clay hollow bricks - Low Percentage Voids - 4 storeys

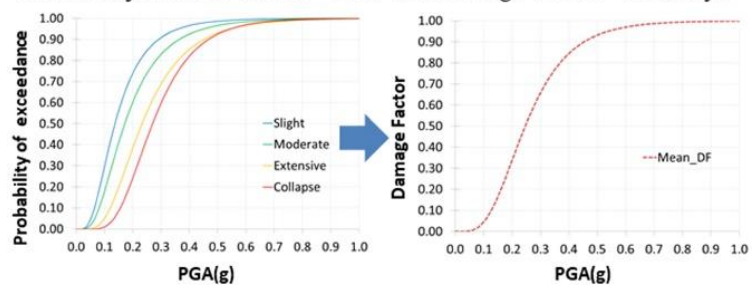

$\operatorname{PGA}(\mathbf{g})$

Stone - 4 storeys

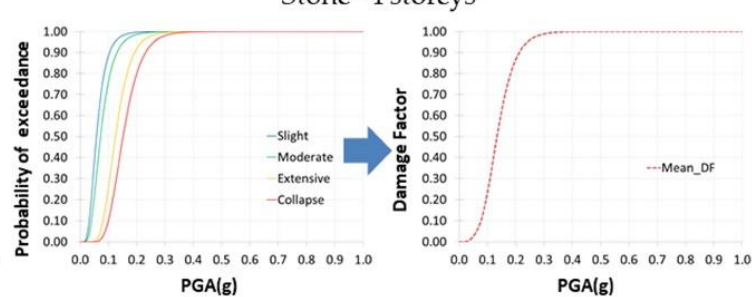

(b)

Figure 8. Vulnerability functions for typical unreinforced masonry buildings of (a) two storeys and

(b) four storeys.

For each assigned vulnerability curve, based on Equations (4)-(6), three graphs of debris width were constructed in order to take into account the different debris distributions along the critical areas of $\mathrm{AC} 1$ and $\mathrm{AC} 2$. These graphs illustrate the debris distribution generated by the interfering buildings constituting the structural aggregates along the road edges of the critical areas. In fact, the debris distribution can affect the following:

(a) Corso Umberto I ( $w_{d}=w_{d, \max }$ on Corso Umberto I);

(b) the roadway opposite Corso Umberto I ( $w_{d}=0$ on Corso Umberto I);

(c) both roads $\left(w_{d}=w_{d, \max } / 2\right.$ on Corso Umberto I).

As indicated in step 3 of Section 2, the graphs of debris width depend on the geometric and typological characteristics of buildings, the collapse model considered, and the IM values for which the OLS $(D F=7 \%)$ and SLC $(D F=80 \%)$ are reached.

Taking into account the geometric characteristics of $\mathrm{AC} 1$ and $\mathrm{AC} 2$ and comparing the debris graphs (18 diagrams for each side of the road), using Equation (10), $324 w_{f r}$ values (number of analyses) were calculated for each IM. Considering the number of points for which $w_{f r} \leq 3.50 \mathrm{~m}$ (or $w_{d r} \geq 2.00 \mathrm{~m}$ ), the number of closures or collapses was identified for each $I M$. Based on the number of analyses and closures or collapses identified for $0.1 \mathrm{~g} \leq I M \leq 0.5 \mathrm{~g}$ (region of the fragility curve most important for risk assessments), using a simple software tool [19] to solve Equation (13), the fragility curve parameters were estimated for AC1 and AC2. Figure 9 shows the fragility curves of the analyzed infrastructure with the relevant construction points. Finally, using Equation (14), the probability that the road was open for the passage of emergency vehicles after debris fall could be defined for each $I M$ (Figure 10). 


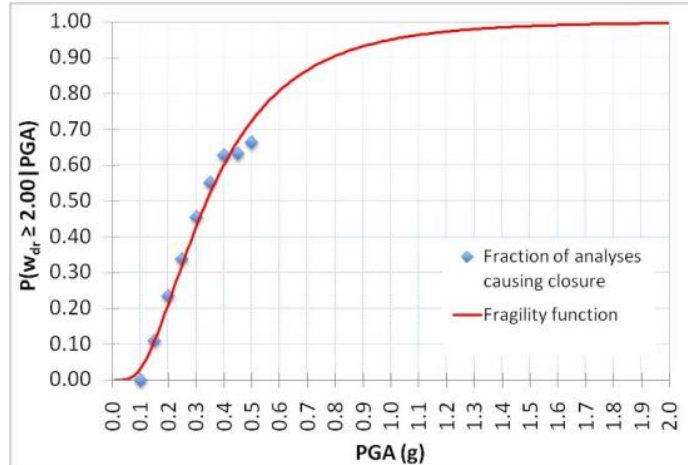

(a)

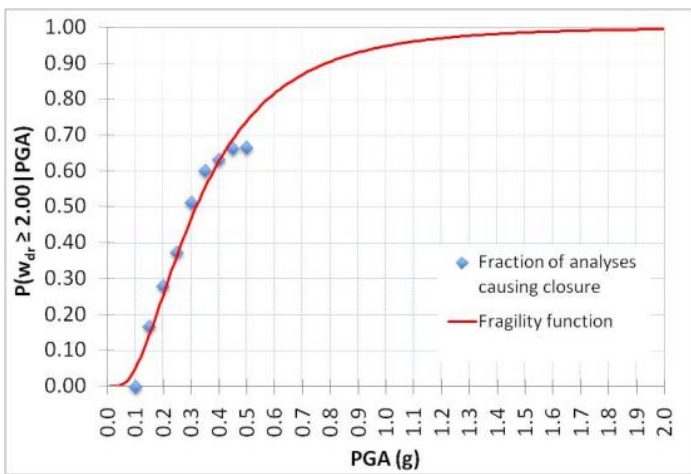

(b)

Figure 9. Fragility curve in terms of probability of closure for (a) AC1 and (b) AC2.

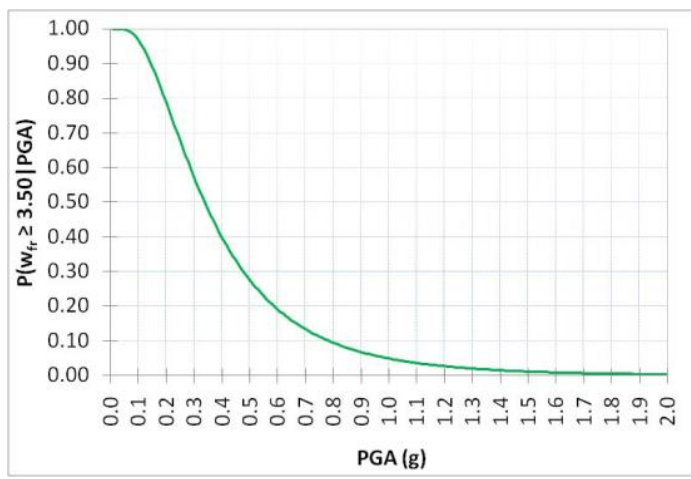

(a)

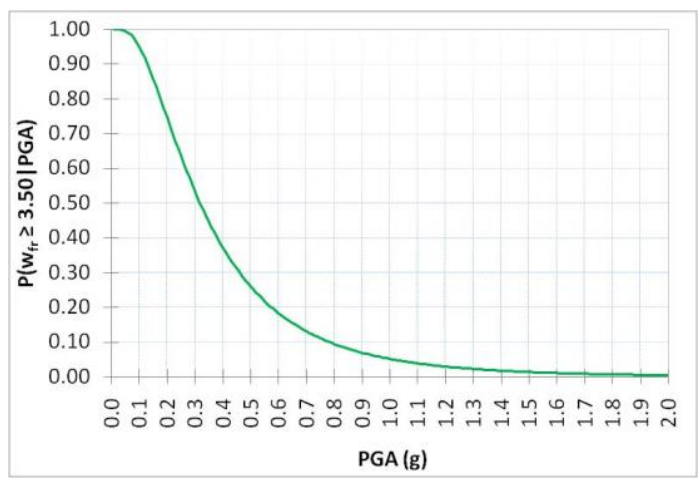

(b)

Figure 10. Fragility curve in terms of probability of opening for (a) AC1 and (b) AC2.

\section{Discussion of the Results}

The seismic events that affected Central Italy in August and October 2016 are among the strongest earthquakes that have happened in that area. Due to the seismic events of 24 August, Amatrice suffered the most extensive in terms of casualties and damage to structures, while the October earthquakes did not cause casualties, because people were already evacuated from damaged houses due to previous seismic events. Based on a field survey performed in Amatrice on 12 September 2016, several authors [20] developed a detailed map of the damage distribution resulting from the seismic events of 24 August. According to these authors, during the first seismic event (the main shock at 3:36 a.m.), the accelerometric station located in the municipality of Amatrice (AMT) recorded a PGA of $0.87 \mathrm{~g}$ along the EW component. The AMT seismic station was located at approximately $450 \mathrm{~m}$ from the town center and $8.5 \mathrm{~km}$ from the epicenter. It was therefore very close to AC1 and AC2 (Figure 11) and consequently, the same IM levels could be considered in the analysis. The map shown in Figure 12 was elaborated from satellite images taken on 25 August [25]. Consistent with the aforementioned authors [20], it shows that along Corso Umberto I, numerous buildings were damaged or collapsed, which caused the complete blockage of AC1 and AC2. 


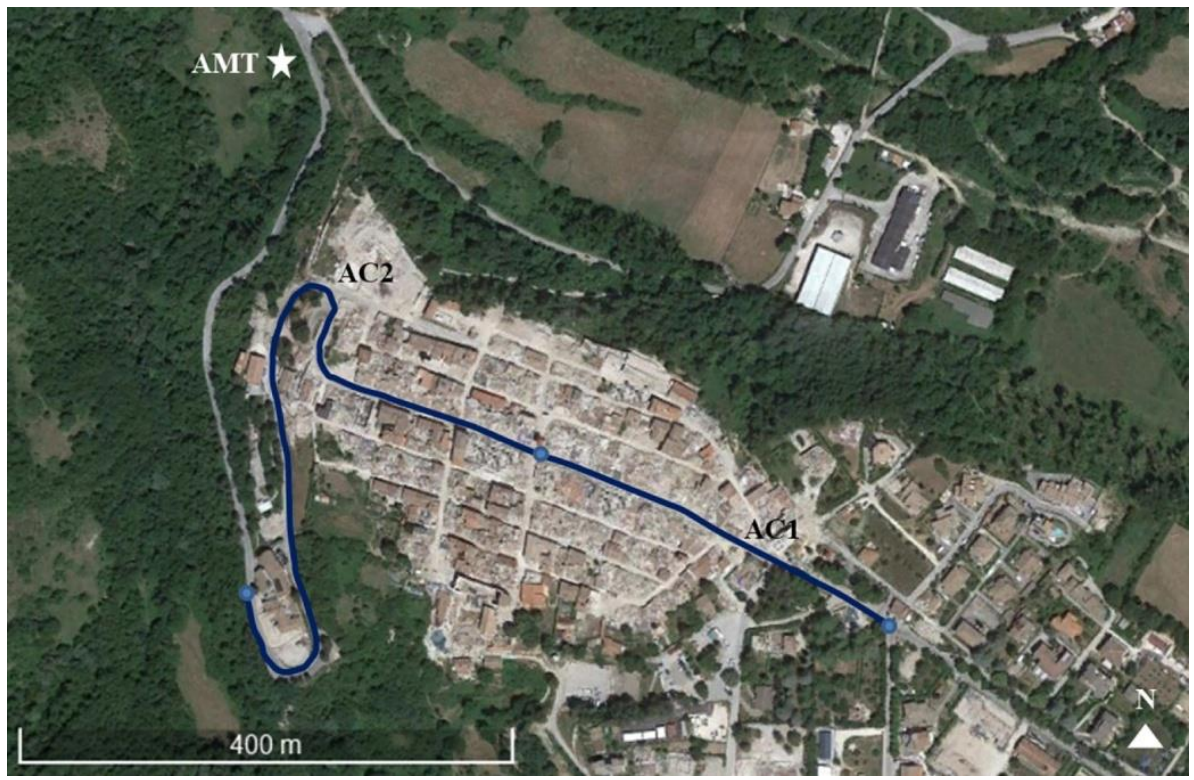

Figure 11. Location of Amatrice (AMT) seismic station and road network segments individuation.

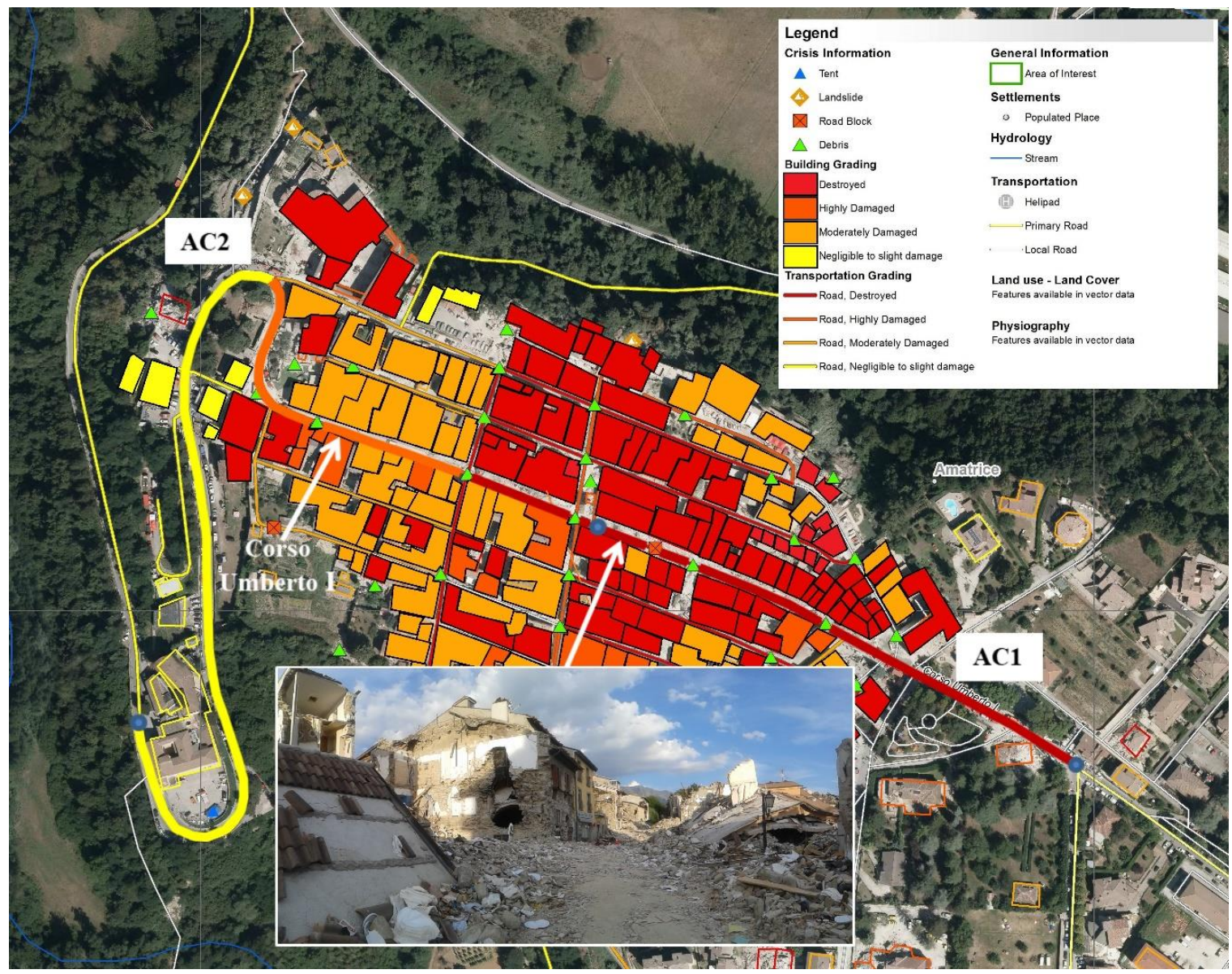

Figure 12. Map of damage along Corso Umberto I [25].

In this study, only the first seismic event $(\mathrm{PGA}=0.87 \mathrm{~g}$ ) was considered, and the cumulative damage effects were neglected. However, based on the literature [20], the damage could be attributed in large part to the first event. As shown in Figure 13, with the PGA value of $0.87 \mathrm{~g}$ on the probability axis of the fragility curves developed for the case study, there was a $93 \%$ probability that the road 
was blocked and, consequently, only a $7 \%$ probability that the road was open for the passage of emergency vehicles. Therefore, the proposed methodology provided a good interpretation of the real data concerning the case examined. The results of the validation carried out slightly underestimated the probability of closure due to the damage accumulated after the main shock.

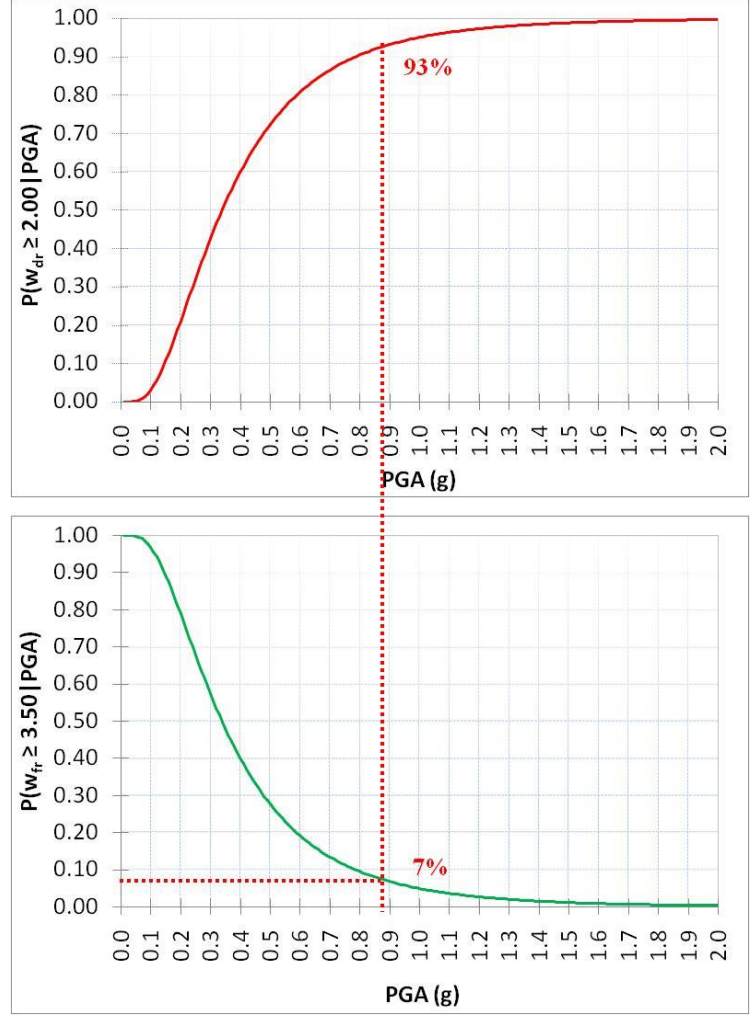

(a)

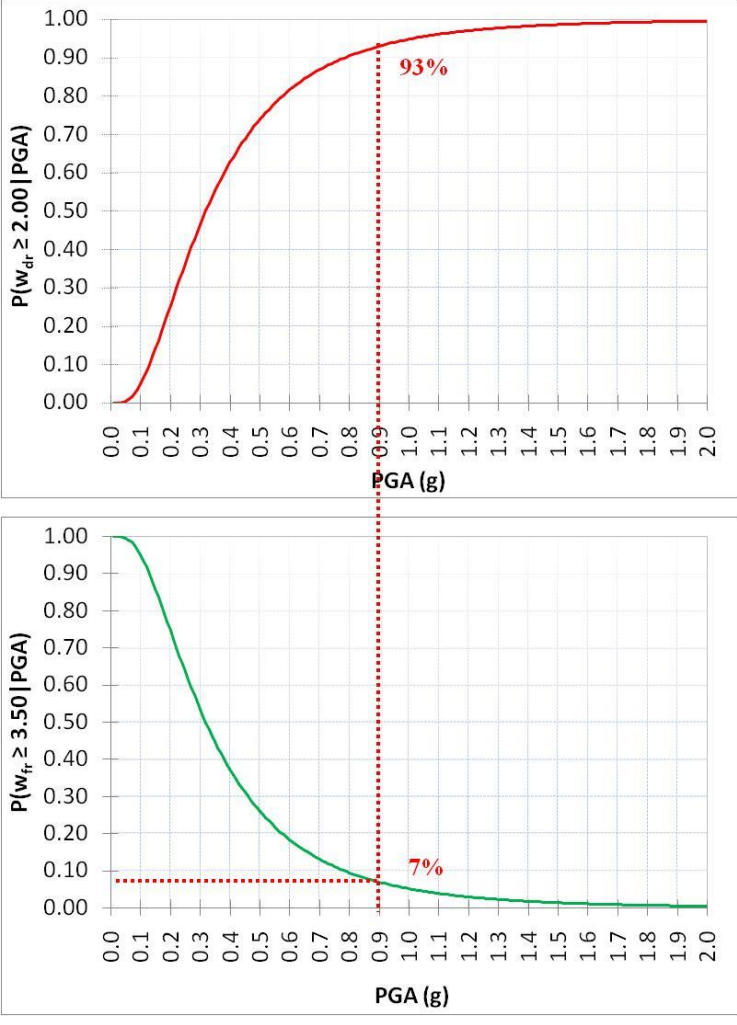

(b)

Figure 13. Comparison of the results with the real case (PGA $=0.87 \mathrm{~g}$ ) for (a) AC1 and (b) AC2.

In order to evaluate the operational efficiency of the emergency management system identified by the LCE analysis through a network of nodes and arcs, it is therefore possible to associate for each node the fragility curve defined for the building (for example using the SMAV methodology [26,27]), and for each urban arc, the fragility curve constructed with the proposed methodology.

The developed fragility curves are defined in terms of PGA following the IM values used for the vulnerability functions of buildings. Through the proposed procedure, the fragility curves of the road network segments can be constructed with other IMs (Housner Intensity, Arias Intensity, etc.) by assigning different vulnerability functions.

\section{Conclusions}

During a disastrous seismic event, the debris of buildings interfering with the road network is the main cause of urban mobility disruption. Nevertheless, the literature that develops fragility curves for infrastructures subject to seismic actions focuses upon geotechnical effects, and does not provide fragility curves based on this important type of road blockage.

For a generic road network segment in an urban area, a fragility curve constructed with the proposed framework can interpret the debris distribution phenomenon of the damaged buildings. More specifically, for a given seismic intensity measure level, the developed fragility curves express the probability that the road is open or closed to the transit of emergency vehicles after the debris fall. The proposed procedure is specifically tailored for the minimum set of information provided by the LCE 
analysis, and is based on the construction of debris graphs and the use of the maximum likelihood estimation method.

If in a road network segment there are also other causes of mobility disruption related, for example, to the damage to bridges, retaining walls, etc., the relevant fragility curves can be assumed to work in series. This implies that the probability of opening (or closure) of the generic road segment is based on the product among the probabilities of opening (or closure) of the various fragility curves interpreting the different phenomena.

In this work, the fragility curves were developed for the portions of road having the highest risk for loss of connectivity (critical areas), but they can be defined by applying the proposed methodology to all portions of a road between two opposite structural aggregates. Additionally, in this case, the fragility curves of the different portions can be assumed to work in series. Such aspects can be valuable for future research. In the current opinion of the authors, it is sufficient to focus on the critical areas of the road network segments, thus avoiding laborious data analysis. In these areas, defining the debris widths according to the geometric characteristics of the entire structural aggregates, the interactions among the debris heaps of the different buildings constituting the aggregates and the relative distribution of the blockages along them can be sufficiently taken into account.

Author Contributions: Conceptualization, A.A.; methodology, A.A.; validation, A.A., F.M. and M.V.; formal analysis, A.A.; investigation, A.A., F.M. and M.V.; data curation, A.A.; writing-original draft preparation, A.A., F.M., M.V.; writing-review and editing, A.A., F.M., M.V.; visualization, A.A.; supervision, F.M. and M.V. All authors have read and agreed to the published version of the manuscript.

Funding: This research received no external funding.

Acknowledgments: This research was supported by the Italian Civil Protection Department within the project "Contratto concernente l'affidamento della Governance in materia di riduzione del rischio sismico e vulcanico ai fini di protezione civile nell'ambito del PON Governance e Capacità Istituzionale 2014-2020-CIG6980737E65". Authors would like to thank Massimiliano Moscatelli of the Italian National Research Council-IGAG, and Fabrizio Bramerini, Sergio Castenetto, Antonella Gorini, Giuseppe Naso and Daniele Spina of the Italian Civil Protection Department for the useful discussions.

Conflicts of Interest: The authors declare no conflict of interest.

\section{References}

1. Ertugay, K.; Argyroudis, S.; Düzgün, H.Ş. Accessibility modeling in earthquake case considering road closure probabilities: A case study of health and shelter service accessibility in Thessaloniki, Greece. Int. J. Disaster Risk Reduct. 2016, 17, 49-66. [CrossRef]

2. Goretti, A.; Sarli, V. Road Network and Damaged Buildings in Urban Areas: Short and Long-term Interaction. Bull. Earthq. Eng. 2006, 4, 159-175. [CrossRef]

3. Dolce, M.; Giovinazzi, S.; Iervolino, I.; Nigro, E.; Tang, A. Emergency management for lifelines and rapid response after L'Aquila earthquake. Seism. Des. J. 2009, 3, 215-223.

4. Argyroudis, S.; Mitoulis, S.; Kaynia, A.M.; Winter, M.G. Fragility assessment of transportation infrastructure systems subjected to earthquakes. In Proceedings of the GEESD V, Geotechnical Special Publication (GSP 292), Austin, TX, USA, 10-13 June 2018.

5. Schweier, C.; Markus, M. Classification of Collapsed Buildings for Fast Damage and Loss Assessment. Bull. Earthq. Eng. 2006, 4, 177-192. [CrossRef]

6. Dolce, M. The Italian national seismic prevention program. In Proceedings of the 15th World Conference on Earthquake Engineering, Lisbon, Portugal, 24-28 September 2012.

7. Dolce, M.; Speranza, E.; Bocchi, F.; Conte, C. Probabilistic assessment of structural operational efficiency in emergency limit conditions: The I.OPà.CLE method. Bull. Earthq. Eng. 2018, 16, 3791-3818. [CrossRef]

8. Brando, G.; De Matteis, G.; Spacone, E. Predictive model for the seismic vulnerability assessment of small historic centres: Application to the inner Abruzzi Region in Italy. Eng. Struct. 2017, 153, 81-96. [CrossRef]

9. Chieffo, N.; Clementi, F.; Formisano, A.; Lenci, S. Comparative fragility methods for seismic assessment of masonry buildings located in Muccia (Italy). J. Build. Eng. 2019, 25, 100813. [CrossRef]

10. Chieffo, N.; Formisano, A. Comparative Seismic Assessment Methods for Masonry Building Aggregates: A Case Study. Front. Built Environ. 2019, 5, 123. [CrossRef] 
11. D'Ayala, D.; Meslem, A.; Vamvatsikos, D.; Porter, K.; Rossetto, T.; Silva, V. Guidelines for Analytical Vulnerability Assessment of Low/Mid-Rise Buildings; Vulnerability Global Component Project; 2015. Available online: https://www.researchgate.net/profile/Dina_DAyala/publication/260552809_GEM_Guidelines_ for_Analytical_Vulnerability_Assessment_of_LowMid-rise_Buildings/links/00b7d537e49481b52e000000/ GEM-Guidelines-for-Analytical-Vulnerability-Assessment-of-Low-Mid-rise-Buildings.pdf (accessed on 5 January 2020).

12. Vona, M.; Manganelli, B.; Tataranna, S.; Anelli, A. An Optimized Procedure to Estimate the Economic Seismic Losses of Existing Reinforced Concrete Buildings due to Seismic Damage. Buildings 2018, 8, 144. [CrossRef]

13. Ministero Delle Infrastrutture e Dei Trasporti. D.M. 28 Febbraio 2017, n. 58 Recante: "Linee Guida per la Classificazione del Rischio Sismico Delle Costruzioni Nonché le Modalità per L'attestazione, da Parte di Professionisti Abilitati, Dell'efficacia Degli Interventi Effettuati"; Ministero Delle Infrastrutture e dei Trasporti: Rome, Italy, 2017. (In Italian)

14. Ministero Delle Infrastrutture e Dei Trasporti. D.M. 7 Marzo 2017, n. 65 Recante: "Linee Guida per la Classificazione del Rischio Sismico Delle Costruzioni e i Relativi Allegati. Modifiche All'articolo 3 del Decreto Ministeriale n. 58 del 28 Febbraio 2017"; Ministero Delle Infrastrutture e Dei Trasporti: Rome, Italy, 2017. (In Italian)

15. NTC 2018: Ministero delle Infrastrutture e dei Trasporti. Aggiornamento Delle Norme Tecniche per le Costruzioni. Part 3.2.2: Categorie di Sottosuolo e Condizioni Topografiche, Gazzetta Ufficiale n. 42 del 20 Febbraio 2018; Ministero Delle Infrastrutture e Dei Trasporti: Rome, Italy, 2018. (In Italian)

16. Domaneschi, M.; Cimellaro, G.P.; Scutiero, G. A simplified method to assess generation of seismic debris for masonry structures. Eng. Struct. 2019, 186, 306-320. [CrossRef]

17. Argyroudis, S. Contribution to Seismic Vulnerability and Risk of Transportation Networks in Urban Environment. Ph.D. Thesis, Aristotle University of Thessaloniki, Thessaloniki, Greece, 2010. (In Greek).

18. Argyroudis, S.; Selva, J.; Gehl, P.; Pitilakis, K. Systemic Seismic Risk Assessment of Road Networks Considering Interactions with the Built Environment. Comput. Aided Civ. Infrastruct. Eng. 2015, 30, 524-540. [CrossRef]

19. Baker, J.G. Efficient analytical fragility function fitting using dynamic structural analysis. Earthq. Spectra 2015, 31, 579-599. [CrossRef]

20. Fiorentino, G.; Forte, A.; Pagano, E.; Sabetta, F.; Baggio, C.; Lavorato, D.; Nuti, C.; Santini, S. Damage patterns in the town of Amatrice after August 24th 2016 Central Italy earthquakes. Bull. Earthq. Eng. 2018, 16, 1399-1423. [CrossRef]

21. Italian Department of Civil Protection Department. Available online: http://www.protezionecivile.gov.it/ jcms/it/terremoto_centro_italia_2016.wp (accessed on 9 October 2017).

22. Web MS-CLE. Available online: http://www.webms.it/servizi/viewer.php (accessed on 9 November 2018).

23. OpenQuake Platform. Available online: https://platform.openquake.org/vulnerability/list?type_of_ assessment=1 (accessed on 9 October 2019).

24. Ahmad, N.; Crowley, H.; Pinho, R. Analytical Fragility Functions for Reinforced Concrete and Masonry Buildings and Buildings Aggregates of Euro-Mediterranean Regions-UPAV Methodology; Internal Report, Syner-G Project 2009/2012; University of Pavia: Pavia, Italy, 2011.

25. Copernicus Emergency Management Service. Available online: http://emergency.copernicus.eu/ (accessed on 5 January 2020).

26. Spina, D.; Acunzo, G.; Fiorini, N.; Mori, F.; Dolce, M. A probabilistic simplified seismic model of masonry buildings based on ambient vibrations. Bull. Earthq. Eng. 2018. [CrossRef]

27. Fiorini, N.; Acunzo, G.; Spina, D.; Falzone, G. Structural Health Assessment of Historical Buildings via Ambient Vibrations: The SMAV Methodology for "Palazzo delleLaudi" at Sansepolcro (AR). Int. J. Archit. Herit. 2019. [CrossRef]

(C) 2020 by the authors. Licensee MDPI, Basel, Switzerland. This article is an open access article distributed under the terms and conditions of the Creative Commons Attribution (CC BY) license (http://creativecommons.org/licenses/by/4.0/). 